\title{
Dependence of paternity rates on alternative reproductive behaviors in the squid Loligo bleekeri
}

\author{
Y. Iwata ${ }^{1, *}$, H. Munehara ${ }^{2}$, Y. Sakurai ${ }^{1}$ \\ ${ }^{1}$ Graduate School of Fisheries Sciences, Hokkaido University, 3-1-1 Minato-cho, Hakodate, Hokkaido 041-8611, Japan \\ ${ }^{2}$ Usujiri Fisheries Station, Field Science Center for Northern Biosphere, Hokkaido University, 152 Usujiri-cho, Hakodate, \\ Hokkaido 041-1613, Japan
}

\begin{abstract}
The mating behavior of captive Loligo bleekeri and the paternity of the resulting progeny were examined based on behavioral observations and genetic analyses. In this species, there are 3 mating behaviors (male-parallel, head-to-head, and extra-pair), and 2 sperm storage sites in females (seminal receptacle and the opening of the oviduct), which suggest that sperm competition occurs. All 3 mating behaviors were observed, and females mated often with different males, resulting in multiple paternity within 3 of the 4 broods examined. In each brood, the male to mate last and frequently before the female spawned fertilized the most eggs (87 to $100 \%$ ). A sneaker male that mated by extra-pair copulation sired $8.5 \%$ of the eggs in a brood. Some eggs were fertilized by sperm received before the start of the study, indicating that sperm can be stored for at least several days before a spawning. In the broods with multiple paternity, the paternity patterns differed among egg capsules. Male competition was more intense between similar-sized males than between differentsized males, but body size did not affect the copulative success in the male-parallel position. We found multiple mating and multiple paternity in L. bleekeri. Paternity rates differed depending on the complex of factors, mating position, timing, frequency and duration. Alternative reproductive behaviors would change these factors and lead to different paternity rates.
\end{abstract}

KEY WORDS: Multiple paternity $\cdot$ Reproductive strategy $\cdot$ Squid $\cdot$ Loligo $\cdot$ Microsatellite $\cdot$ Sperm competition

\section{INTRODUCTION}

Loliginid squids are important members of nearshore and continental shelf ecosystems, and are fished commercially worldwide. The fisheries tend to target spawning aggregations in shallow waters, so information on their reproductive strategies is needed to assess how the fisheries impact the squid populations (Hanlon 1998). One of the commercially most important loliginids in Japan is Loligo bleekeri Keferstein. It occurs widely in coastal waters from southern Korea to northern Japan (Roper et al. 1984), it has a 1 yr life span, and its spawning season continues over a 6 mo period (Natsukari \& Tashiro 1991). Like other loliginids, L. bleekeri is a demersal spawner, and, at 1 spawning, lays up to 30 egg capsules, each containing approximately 50 eggs (Natsukari \& Tashiro 1991).

Loliginid squids mate in 2 main positions: 'head-tohead' and 'male-parallel' (Drew 1911, Hanlon \& Messenger 1996). In the head-to-head position, the male deposits spermatophores in or near the female's seminal receptacles, which are located near her mouth. In the male-parallel position, the male deposits spermatophores inside the female's oviduct in the mantle cavity.

Immature loliginid females mate in the head-to-head position and store sperm in their seminal receptacle (Drew 1911). On loliginid spawning grounds, large males form temporary pairs with mature females, which give the males preferred access to the female 
just before she spawns (Hanlon et al. 1997, 2002). These consort males guard females before and after copulation and while the females spawn, but sometimes large intruders replace the consort males and copulate with the females (Hanlon et al. 1997, 2002). Furthermore, extra-pair copulations (EPCs) also occur, in which a small 'sneaker male' copulates with a female that is paired with another male by attaching spermatophores near the female's mouth (Hanlon 1996, 1998, Hanlon et al. 1997, 2002). The spermatozoa are stored until they are released at spawning, so loliginid females can use spermatozoa from several males when they spawn.

When squids spawn, eggs are extruded from the oviduct and pass through the funnel to a position near the mouth. The eggs can be fertilized either as they leave the oviduct, by spermatozoa placed in the mantle cavity during a male-parallel mating, or near the mouth, by spermatozoa stored in the seminal receptacle after a head-to-head mating or EPC. This difference in the fertilization mechanism will presumably affect the reproductive success of each copulative behavior and play a role in sexual selection (Birkhead \& Møller 1998).

If the reproductive success of each copulative behavior differs, males will compete to mate in the favorable position. Agonistic behavior between males has been shown to escalate through several phases, from visual signaling to physical contact (DiMarco \& Hanlon 1997). In the most escalated phase of a contest, a male will rush at another male and sometimes grab it (King et al. 1999). The relative sizes of males affect the outcome of these contests (DiMarco \& Hanlon 1997). When competitive abilities of competing individuals differ, alternative reproductive tactics might increase the fitness of low-competitive-status males (Gross 1996) and lead to the evolution of phenotypic diversity in males, such as large fighters and small sneakers (Moczek \& Emlen 2000).

Parentage analysis is a valuable tool to understand reproductive systems, including sperm competition. Microsatellite DNA analyses of several loliginid squids have shown that the eggs within individual egg capsules are usually sired by multiple males (Loligo forbesi: Shaw \& Boyle 1997, Emery et al. 2001; L. pealei: Buresch et al. 2001; L. vulgaris reynaudii: Shaw \& Sauer 2004). In those studies, mating was not observed, so it is not known if or how the mating behavior is related to reproductive success. A combined approach using both behavioral observations in the captive condition and genetic analysis can provide important information about the mechanism of sperm storage, release, and fertilization for each mating position (sperm storage site). Furthermore, previous studies analyzed only 1 or 2 egg capsules for each female even though females generally spawn many egg capsules ( 20 to 100 in L. pealeii, Maxwell \& Hanlon 2000). The utilization pattern of spermatozoa stored inside the mantle cavity and those stored in the seminal receptacle probably differ among egg capsules, so parentage analysis of all egg capsules spawned is needed to accurately determine the parentage rates of the different mating behaviors.

In this study, we observed the mating behavior of captive Loligo bleekeri and analyzed the paternity of subsequently spawned eggs to determine (1) if mating with >1 male results in multiple paternity, (2) the parentage rates of the 3 mating behaviors (male-parallel, head-to-head, and EPCs), (3) if the paternity pattern differs among egg capsules from a single spawning, and (4) if male body size affects copulative success and mate guarding intensity.

\section{MATERIALS AND METHODS}

Reproductive behavior. From January to May 2003, squids were caught from inshore set nets in southern Hokkaido to observe their reproductive behavior. To investigate the difference in paternity rates among the alternative reproductive behaviors, we introduced 1 female and 2 males into a race-way aquarium $(5.5 \times 2.5$ $\times 1 \mathrm{~m}$ depth, $13000 \mathrm{l}$ ) at the Usujiri Fisheries Station, Field Science Center for Northern Biosphere, Hokkaido University. Each individual was used only once, and 1 male randomly selected from the 2 was marked with a tiny plastic ribbon tag on 1 of its fins for individual identification. A cube-shaped structure made from steel pipes $(0.5 \times 0.5 \times 0.5 \mathrm{~m}$, with 3 sides covered with polyethylene mesh nets) was set on the bottom of the aquarium as a spawning substrate.

The mantle lengths (ML) of all individuals were measured before the experiments, and body weights, gonad weights, and accessory gland weights were measured after the experiment. The maturity stages of all individuals were determined according to the maturity stage indices in Loligo plei (Perez et al. 2002). All males were classified in the mature stage; in each male, the testis and spermatophoric organs were enlarged, there were many spermatophores in the accessory gland, and none had an excessively low gonad weight (Table 1). As a result, all males were considered fertile, and none were considered to be exhausted. Muscle tissues were sampled from the gills for genetic analysis. Three trials were conducted, and the body size ratio between the 2 males (calculated as the ML of the larger male / the ML of the smaller male) was 1.01 in Trial A, 1.18 in Trial B, and 1.40 in Trial C (Table 1).

The behavior of all squid in each experiment was recorded on videotape and analyzed from the start of 
Table 1. Loligo bleekeri. Morphological characters of the male squid used in each trial (gonad weight, testis weight + accessory organ weight; GSI, gonad weight/body weight $\times 100$; Body size ratio, mantle length of the larger male/ mantle length of the smaller male)

\begin{tabular}{|lcccccc|}
\hline & $\begin{array}{c}\text { Male } \\
\text { ID }\end{array}$ & $\begin{array}{c}\text { Mantle } \\
\text { length (mm) }\end{array}$ & $\begin{array}{c}\text { Body } \\
\text { weight (g) }\end{array}$ & $\begin{array}{c}\text { Gonad } \\
\text { weight }(\mathrm{g})\end{array}$ & GSI & $\begin{array}{c}\text { Body size } \\
\text { ratio }\end{array}$ \\
\hline Trial A & A-M1 & 276 & 218 & 5.24 & 2.40 & 1.01 \\
& A-M2 & 272 & 219 & 4.98 & 2.27 & \\
Trial B & B-M1 & 253 & 234 & 4.98 & 2.13 & 1.18 \\
& B-M2 & 215 & 113 & 3.82 & 3.38 & \\
Trial C & C-M1 & 303 & 173 & 5.20 & 3.01 & 1.40 \\
& C-M2 & 217 & 126 & 2.92 & 2.32 & \\
\hline
\end{tabular}

capsule in Trial B had only 7 eggs) and 390 offspring were genotyped, respectively. Including the 9 adults used for behavioral analysis, a total of 47 adults collected from the same location were also genotyped at all loci for population allele-frequency data.

Gill tissue samples dissected from the 47 adults and the whole body of each paralarvae were homogenized by overnight incubation at $50^{\circ} \mathrm{C}$ in a solution of $100 \mathrm{mM}$ Tris-HCl (pH 8.0), $10 \mathrm{mM}$ EDTA (pH 7.5), 1.4 M NaCl, 2\% nhexadecyltrimethylammonium bro-

the experiment until $1 \mathrm{~h}$ after the beginning of spawning. The total observation time was $34 \mathrm{~h}$ in Trial A, $2 \mathrm{~h}$ in Trial B, and $63 \mathrm{~h}$ in Trial $\mathrm{C}$. The time at which each mating occurred and the duration of each male-parallel mating and EPC were recorded (head-to-head mating always lasted $<1 \mathrm{~s}$ ). Agonistic behavior between males was recorded from $1 \mathrm{~h}$ before the beginning of spawning until $1 \mathrm{~h}$ after the beginning of spawning. During this period, the numbers of rushes (a sudden approach toward another male) and grabs (the grasping of another male), which is the most escalated behavior in contests between males, were recorded. Red lamps were used for nighttime observations (18:00 to $06: 00 \mathrm{~h})$.

Microsatellite DNA analysis. Spawned egg capsules were removed from the aquarium and kept separately in $500 \mathrm{ml}$ bottles with circulating water at $12^{\circ} \mathrm{C}$ until the paralarvae hatched about 2 mo later. The paralarvae were collected daily and stored at $-20^{\circ} \mathrm{C}$. In Trial A, all 47 offspring from 5 capsules were genotyped. In Trial B (30 egg capsules) and Trial C (39 egg capsules in 2 spawnings), 10 offspring were randomly selected from each capsule, and 297 offspring (1 egg mide, $0.2 \%$ 2-mercaptoethanol, and $150 \mu \mathrm{g}$ proteinase $\mathrm{K} \mathrm{ml}^{-1}$. DNA in the samples was extracted with phenolchloroform and then precipitated in ethanol. Four previously published microsatellite primers (Lb1, Lb3, Lb4, Lb5; Iwata et al. 2003) and 1 primer newly developed for the present study (Lb6) were used for genotyping (Table 2). All parents were genotyped at the 5 microsatellite loci, and the 3 loci at which 2 males in each trial were found not to share an allele were used for paternity analysis (Table 2). The experimental procedures used during the PCR (polymerase chain reaction) and visualization of the products followed Iwata et al. (2003). The genotype of each paralarvae was verified by electrophoresing the PCR products through a polyacrylamide gel.

Paternity analysis. Deviations of the observed heterozygosities at each locus from the HardyWeinberg expectations and genotypic linkage disequilibrium were tested using exact tests with significance determined by the Markov chain method (GENEPOP v3.4; Raymond \& Rousset 1995). Expected exclusion probabilities with 1 known parent, which indicate the probabilities that 2 randomly selected

Table 2. Loligo bleekeri. Characteristics of the microsatellite loci used for parentage analysis ( $H_{\mathrm{O}}$ : observed heterozygosity; $H_{\mathrm{E}}$ : expected heterozygosity; p: probability of departure from Hardy-Weinberg expected genotype ratios; EEp: expected exclusion probability with a known parent; O: locus used for parental analysis in each trial; DDBJ: DNA Data Bank of Japan). A total of 47 individuals were genotyped for each locus

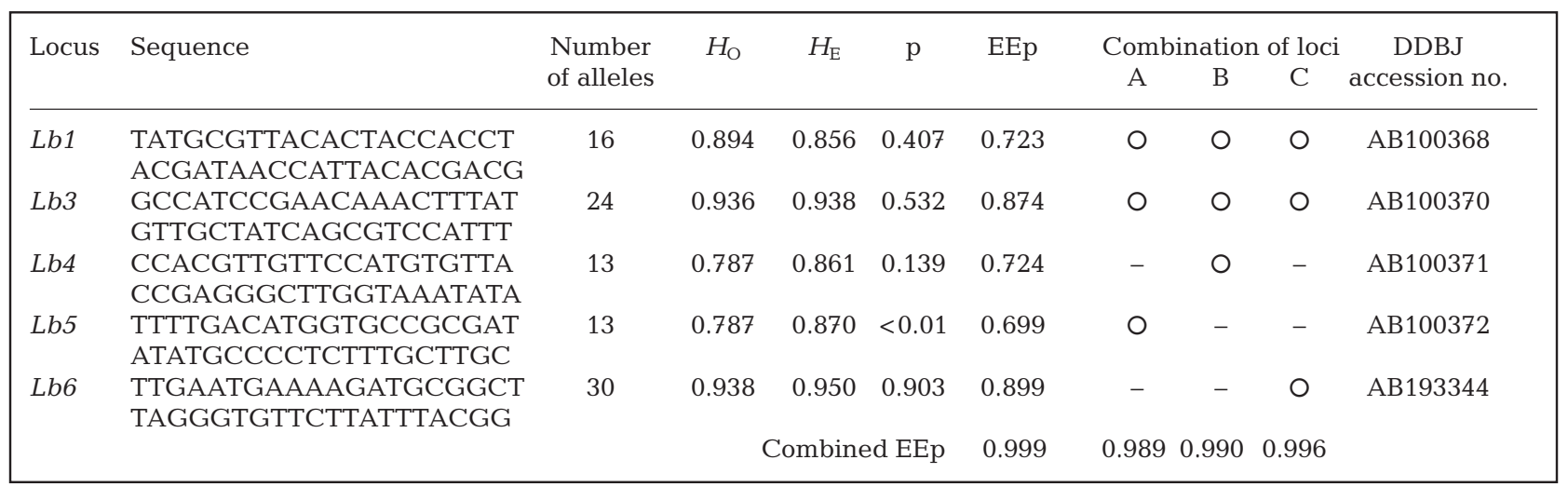


individuals from a population do not have the same genotypes at 1 or several loci, were calculated using the computer program GERUD1.0 (Jones 2001). If the expected exclusion probability is sufficiently high, the possibility of paternal misidentification and confusion between experimental and field males is low.

As the females may have mated before they were collected, we used a multi-locus method to estimate the minimum number of fathers and the parentage rate of each male. This analysis was also conducted using GERUD1.0. This program identifies paternal alleles using 2 offspring alleles and known maternal alleles (if both alleles of an offspring have the same genotype as the mother, then the father shares 1 or 2 alleles with the mother; thus, paternal contribution will be ambiguous within the 2 alleles, and both alleles will be put up as candidates for paternal alleles) and determines the combination of all possible multi-locus paternal genotypes observed in a brood. If the program obtains multiple combinations of multi-locus genotypes with the minimum number of fathers, the likelihood is ranked based on 2 criteria: (1) the summarized $\chi^{2}$ values calculated for each father at each locus based on an assumed 1:1 Mendelian inheritance ratio and (2) the combined expected frequency assuming the HardyWeinberg equilibrium obtained from population allele frequencies.

The frequencies of the offspring's maternal genotypes in each brood were tested to determine if the maternal alleles deviated significantly from a 1:1 Mendelian inheritance ratio, if the mother was heterozygous, and if the mother did not share both alleles with the father. All offspring were assigned to fathers using the most probable paternal genotypes. If the combination of paternal multi-locus genotypes coincided completely with the genotype of an experimental male, that male was considered to be the father. The number of offspring sired by each father in each capsule was estimated by multiplying the parentage rate within 10 offspring from each capsule by the number of eggs in the capsule. The total estimated number of eggs sired in all egg capsules was then used to determine the total parentage rate for each male. If multiple paternity was observed, the deviation of the total parentage rate of each male from equal allocation and the difference of the parentage rate of each male between egg capsules were tested with the $\chi^{2}$-test.

\section{RESULTS}

\section{Reproductive behavior}

In Trial $\mathrm{A}$, the female spawned twice during the $2 \mathrm{~d}$ of observation. Before the first spawning, one male
(A-M2) mated in the male-parallel position (mating duration $=439 \mathrm{~s}$ ) just before the spawning, and the other one (A-M1) mated twice by brief EPCs ( 3 and $5 \mathrm{~s}$ ) as A-M2 was mating (Table 3). Before the second spawning, A-M1 mated in the head-to-head position 100 min before the spawning and in the male-parallel position (388 s) just before the spawning, while A-M2 mated by extended EPCs (223 and 40 s) during the male-parallel copulation by A-M1 (Table 3). The last male to transfer spermatophores inside the female's mantle cavity was A-M1, and the last male to transfer spermatophores near the seminal receptacle was A-M2. All eggs from the first spawning died in the embryonic stage, so only those from the second spawning were used in paternity analysis. The second spawning comprised 47 eggs in 5 capsules, and all eggs were fertilized.

In Trial B, 1 male (B-M2) mated in both the male-parallel (23 s) and head-to-head positions (Table 3). The female spawned 1060 eggs in 30 capsules, and all but 1 egg were fertilized.

In Trial $\mathrm{C}$, the female spawned twice during the $3 \mathrm{~d}$ of observation. Before the first spawning, the male C-M2 mated in the male-parallel (428 s) and head-tohead positions (Table 3). After the first spawning, this same male frequently mated in the head-to-head position (Table 3). Just before the second spawning, C-M2 and C-M1 alternately mated in the male-parallel position (Table 3), but C-M2 mated for much longer periods (C-M2: 435 and $323 \mathrm{~s}$; C-M1: $23 \mathrm{~s}$ ). The last male to transfer spermatophores inside the female's mantle cavity and near the seminal receptacle before second spawning was C-M2. The first spawning comprised 1237 eggs in 27 capsules, and the second comprised 445 eggs in 12 capsules. The fertilization rates of the first and second spawnings were 99.2 and $99.6 \%$, respectively.

The occurrence of rushes and grabs was much higher between similar-sized squid than between different-sized squid (Fig. 1). Between males of similar size (Trial A), rushes and grabs were most often performed by males that mated in the male-parallel position. Between males of different sizes (Trials B and C), rushes and grabs were performed most often by larger males on smaller males regardless of whether the larger males successfully copulated in the maleparallel position or not. The frequency of rushes and grabs increased as the size difference between males increased (Fig. 1).

\section{Paternity analysis}

The numbers of alleles of each locus observed in the 47 adults ranged from 13 to 30, and observed hetero- 
Table 3. Loligo bleekeri. Type and the duration (seconds) of mating behavior that occurred before each spawning, and paternity parentage for each male (MP: male-parallel copulation; EPC: extra-pair copulation; HH: head-to-head copulation; ND: eggs in the first spawning in Trial A were not analyzed because most died in the embryonic stage)

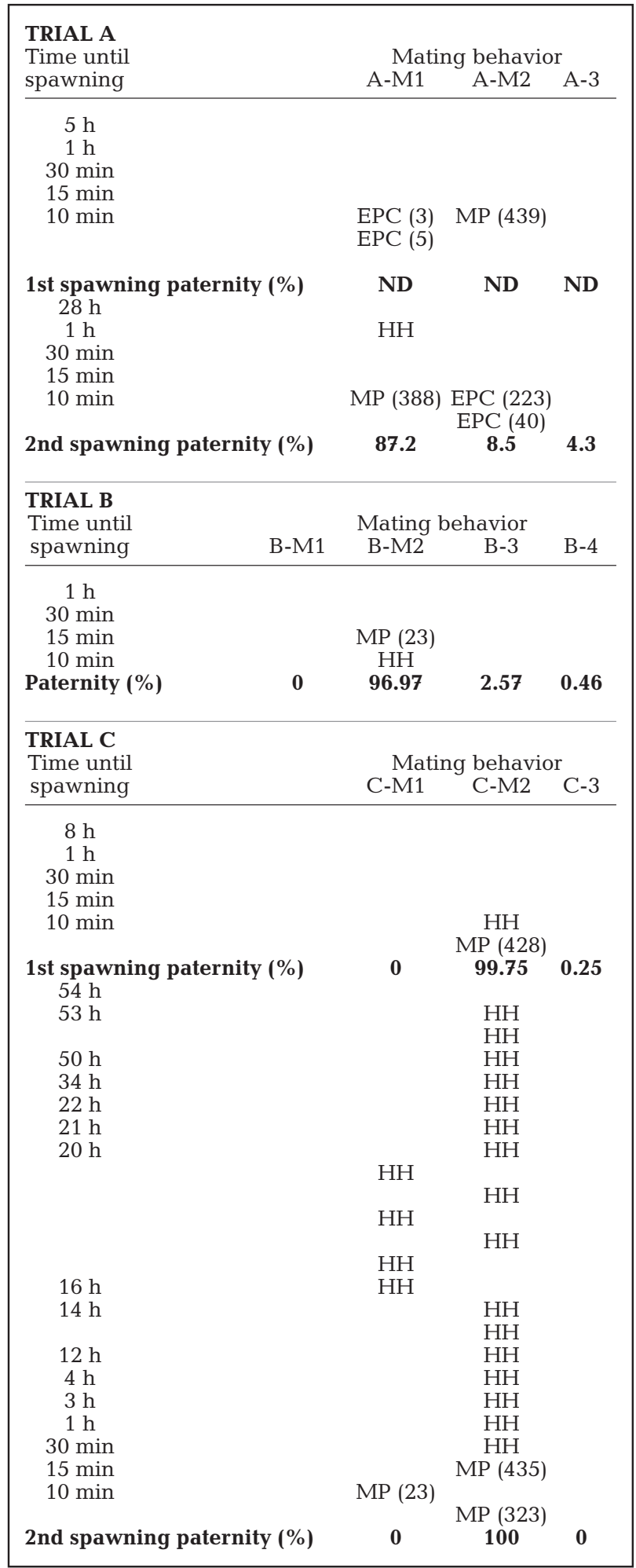

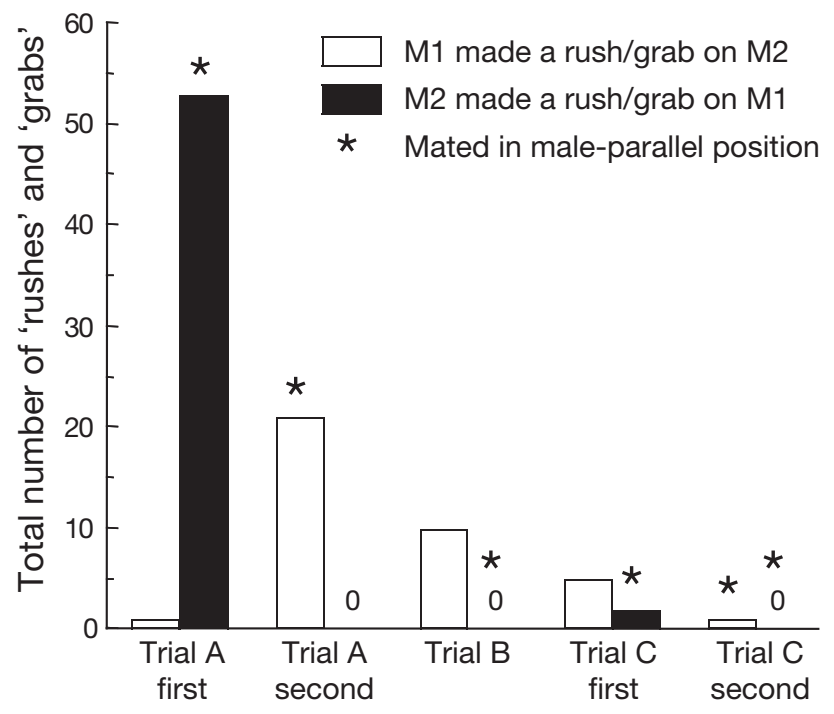

Fig. 1. Loligo bleekeri. Total number of rushes and grabs made by males on the other male present from $1 \mathrm{~h}$ before beginning of spawning until $1 \mathrm{~h}$ after beginning of spawning. The body size ratio of the 2 males was 1.01 in Trial A, 1.18 in Trial B, and 1.40 in Trial $\mathrm{C}$, and M1 was larger than M2 in Trials B and C

zygosities of each locus ranged from 0.787 to 0.938 (Table 2). One locus (Lb5) significantly deviated from Hardy-Weinberg expectations, and the frequency of observed homozygosities was more than expected (Table 2). One possible reason for this result is the presence of null alleles (non-amplifying alleles). In Trial A, in which locus Lb5 was analyzed, the maternal genotypes were heterozygous and all offspring had one of the maternal alleles, indicating that the mother did not have null alleles. One of the candidate fathers was homozygous (A-M1). If the father has null alleles, the offspring genotypes will be homozygous with maternal allele. Five offspring were homozygous with the maternal allele in Trial A. Considering the correlation between alleles of other multiple loci and assuming the Mendelian inheritance ratio, 3 of the 5 offspring were determined to be fertilized by A-M2, which had the same allele as one of the maternal genotype, and the remaining 2 offspring were fertilized by an unknown male, which had the same allele as 1 of the maternal genotype or a null allele (see later paragraph of 'Results'). All homozygous offspring genotypes were checked by reamplification at least twice.

Expected exclusion probabilities with 1 known parent ranged from 0.699 to 0.899 , and those calculated from each of the 3 loci ranged from 0.989 to 0.996 (Table 2). These expected exclusion probabilities were sufficiently high, so the possibility of paternal misidentification and confusion between experimental and field males was extremely low. 
All offspring were successfully genotyped, and each shared one of the maternal alleles at every locus. The frequency of the offsprings' maternal genotypes in each brood did not significantly differ from a 1:1 Mendelian inheritance ratio in all tested alleles (Table 4). Multiple paternities were found in 3 of the 4 broods genotyped, and the highest male parentage rate in each trial was $\geq 87 \%$. The minimum estimated numbers of fathers for each brood were 3 in Trial A, 3 in Trial B, 2 in Trial C (first spawning), and 1 in Trial C (second spawning).

In Trial A, the last male to mate in the male-parallel position (A-M1) sired 41 offspring $(87.23 \%$ of the brood), the sneaker male (A-M2) sired 4 offspring $(8.51 \%)$, and another male that mated before the start of the experiment (A-3) sired 2 offspring $(4.26 \%$, Table 3). The parentage rate of A-M1 differed significantly from those of A-M2 and A-M3 $\left(\mathrm{df}=2, \chi^{2}=61.57\right.$, $\mathrm{p}<0.001$ ), but A-M2 and A-3 did not differ significantly $\left(\mathrm{df}=1, \chi^{2}=0.67, \mathrm{p}=0.689\right)$. Parentage rates of each male did not significantly differ between egg capsules $\left(\mathrm{df}=4, \chi^{2}=1.89, \mathrm{p}=0.879\right.$, the 2 capsules that contained $<5$ eggs were excluded from the analysis, Fig. 2).

In Trial B, the male that mated for a short time in the male-parallel and head-to-head positions (B-M2) sired 288 of the 297 genotyped eggs $(96.97 \%$, the total parentage rates) and the other male (B-M1) sired no eggs. In addition, 2 males that mated before the start of the experiment (B-3, B- 4$)$ sired 8 eggs $(2.57 \%)$ and 1 egg $(0.46 \%)$, respectively (Table 3$)$. The parentage

Table 4. Loligo bleekeri. Frequency of offspring's maternal genotypes in each brood

\begin{tabular}{|c|c|c|c|c|c|c|}
\hline & Alleles & $\begin{array}{l}\text { Female } \\
\text { genotypes }\end{array}$ & $\begin{array}{l}\text { Offspring } \\
\text { genotypes }\end{array}$ & $\begin{array}{l}\text { s maternal } \\
\text { (frequency) }\end{array}$ & $\chi^{2}$ & $\mathrm{p}$ \\
\hline \multirow[t]{3}{*}{ Trial A } & $L b 1$ & $154 / 158$ & \multicolumn{2}{|c|}{154 or $158(47)^{\mathrm{a}}$} & - & - \\
\hline & Lb3 & $133 / 175$ & $133(22)$ & 175 (25) & 0.19 & 0.66 \\
\hline & Lb5 & $104 / 124$ & $104(28)$ & 124 (19) & 1.72 & 0.19 \\
\hline \multirow[t]{3}{*}{ Trial B first } & $L b 1$ & $150 / 150$ & \multicolumn{2}{|c|}{$150(270)^{\mathrm{b}}$} & - & - \\
\hline & $L b 3$ & $157 / 163$ & 157 (137) & $163(133)$ & 0.06 & 0.81 \\
\hline & Lb5 & $171 / 199$ & $171(135)$ & 199 (135) & 0.00 & 1.00 \\
\hline \multirow[t]{3}{*}{ Trial B second } & $L b 1$ & $150 / 150$ & \multicolumn{2}{|c|}{$150(120)^{\mathrm{b}}$} & - & - \\
\hline & $L b 3$ & $157 / 163$ & $157(68)$ & $163(52)$ & 2.13 & 0.14 \\
\hline & Lb5 & $171 / 199$ & $171(51)$ & 199 (69) & 2.70 & 0.10 \\
\hline \multirow[t]{3}{*}{ Trial C } & $L b 1$ & $152 / 160$ & $152(157)$ & $160(140)$ & 0.97 & 0.32 \\
\hline & $L b 3$ & $135 / 167$ & $135(158)$ & 167 (139) & 1.22 & 0.27 \\
\hline & $L b 4$ & $170 / 170$ & \multicolumn{2}{|c|}{$170(297)^{\mathrm{b}}$} & - & - \\
\hline \multicolumn{7}{|c|}{$\begin{array}{l}\text { a Statistical tests could not be conducted because both maternal alleles were } \\
\text { the same as } 1 \text { of the fathers (A-M1; 154/158) and it could not be confirmed } \\
\text { which allele was inherited from the mother } \\
\text { b Statistical tests could not be conducted because the mothers were homozy- } \\
\text { gous on the alleles }\end{array}$} \\
\hline
\end{tabular}

rates differed significantly among the 3 males $(\mathrm{df}=2$, $\left.\chi^{2}=15.13, \mathrm{p}<0.001\right)$ and between B-3 and B-4 $(\mathrm{df}=1$, $\chi^{2}=0.67, p=0.689$ ). All eggs in 23 of the 30 capsules were sired by the male that mated in the male-parallel position (B-M2); eggs in the remaining 7 capsules were sired by B-M2 and another male. Among these 7 egg capsules, the parentage rate of each male significantly differed (df $=12, \chi^{2}=36.91, p<0.001$, Fig. 3 ), but the parentage of eggs fertilized by B-M2 in each capsule did not differ significantly ( $d f=6, \chi^{2}=6.69$, $p=0.361$ ).

In the first spawning of Trial C, the male (C-M2) that mated both in the male-parallel and head-to-head position sired 269 of the 270 genotyped eggs (99.75\%), and the remaining 1 egg $(0.25 \%)$ was sired by a male that mated with the female before the start of the experiment (C-3, Table 3). In the second spawning of Trial $\mathrm{C}$, the male that mated for a short time in the male-parallel position (C-M1) sired no eggs, and all genotyped eggs were sired by C-M2, which was the last to mate in both the male-parallel and head-to-head positions (Table 3).

\section{DISCUSSION}

Loligo bleekeri females copulated multiple times with different males, resulting in multiple paternity within broods. All 3 females used sperm received during mating in the field before they were captured to fertilize their eggs, indicating that sperm stored for several days before spawning were competitive for fertilization. In Trial A, a male that copulated in the field before the first spawning (A-3) sired some eggs in the second spawning, indicating that stored sperm would be competitive for fertilization in several spawnings. Multiple paternity has been reported in other loliginid species, and those studies show that paternities of each male are asymetric, e.g. one of the males sired most of the eggs in a capsule (Buresch et al. 2001, Emery et al. 2001, Shaw \& Sauer 2004). Field observations have shown that large loliginid males guard females after copulation (Hanlon et al. 1997, 2002), and, in L. vulgaris reynaudii, a male that guarded a pre-spawning female had a high parentage rate (Shaw \& Sauer 2004). If the last male to mate fertilizes the most eggs, postcopulatory-guarding behavior is an effective strategy for that male to increase his fitness even with the guarding cost (Yamamura 1986). The mechanisms of 


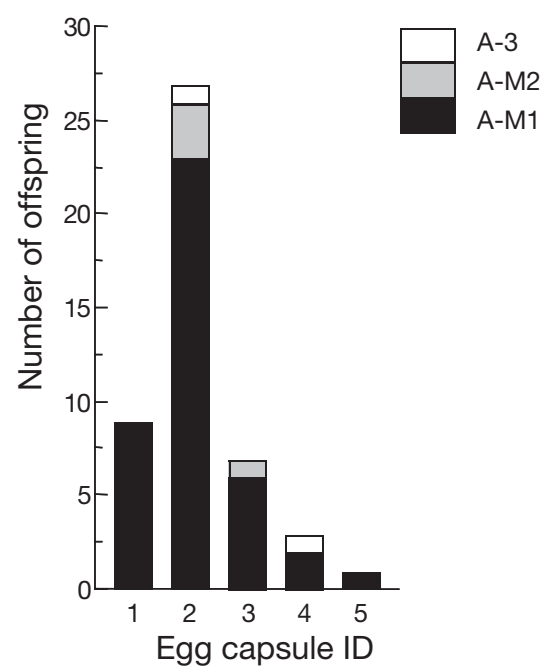

Fig. 2. Loligo bleekeri. Number of offspring sired by each father for the second spawning in Trial A

sperm precedence in loliginid squids are not known, but behavioral observations predict that the final male to mate before a female spawns will sire the most eggs (Hanlon et al. 2002). In the present study, the mating prior to the experiment resulted in fairly low paternity; in each trial, the male that sired most of the eggs (87 to $100 \%$ ) was the male to mate last and frequently with the female before she spawned. Our results were not strong enough to predict a last-male precedence, but we could not exclude this possibility either, because, in the present study, the last male mated frequently, which could have led to the high paternity found, and

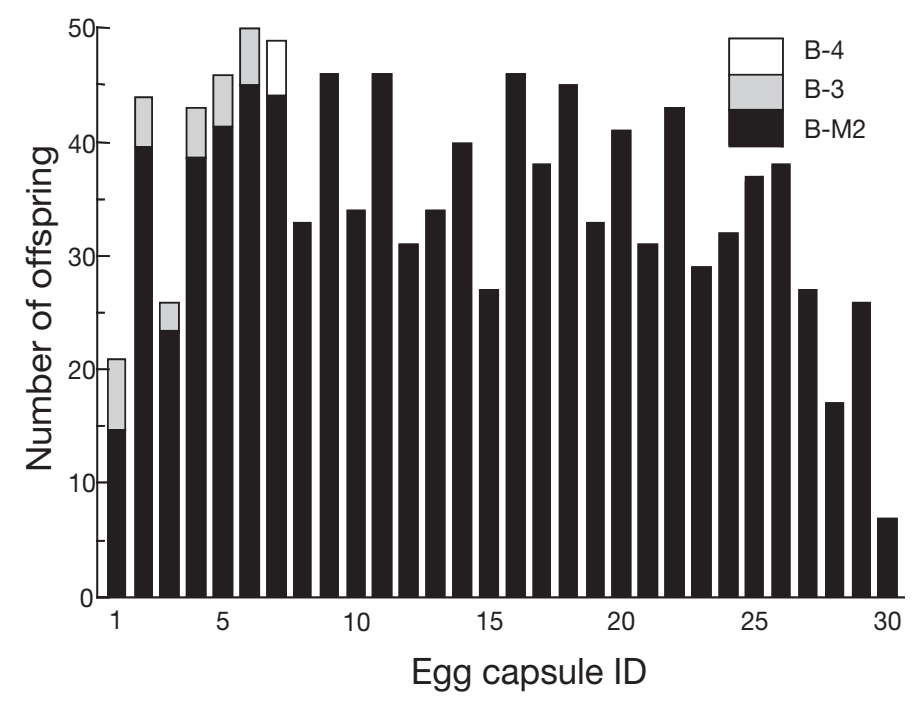

Fig. 3. Loligo bleekeri. Parentage rates of each father for 30 egg capsules in Trial $\mathrm{B}_{\text {; }} 10$ eggs were randomly selected and genotyped in each egg capsule, and the number of offspring sired by each father was calculated using the parentage rate and the number of eggs in each egg capsule the position, duration, and frequency of mating in the field were unknown. For example, both males mated in the male-parallel position alternatively in the second spawning of Trial $\mathrm{C}$, and the last male that mated in the male-parallel position fertilized all eggs. But the last male also mated in the head-to-head position frequently, and the sperm transferred near the seminal receptacle would contribute his paternity in part. A larger sample of females having various mating histories is needed to confirm last-male precedence.

The parentage rates of the most successful male in each trial (87 to $100 \%$ ) were higher than those reported for other loliginids (62 to $76 \%$, summarized in Shaw \& Sauer 2004). There are 2 possible explanations for this difference. First, the captive conditions in the present study prevented the females from mating with more males and facilitated remating with the same males. Second, the mating duration in the male-parallel position in the present study (mean \pm SD: $294 \pm$ 189 s) was much longer than that reported in other loliginid species (Loligo vulgaris reynaudii: range 2 to 39 s, L. pealei: 5 to 20 s, summarized in Hanlon \& Messenger 1996). Prolonged copulation ( 300 s) has previously been reported in L. bleekeri (Hamabe \& Shimizu 1957) and appears to be characteristic of this species. Males that perform prolonged copulation can reduce sperm competition with other males by reducing access to the female before she spawns (copulatory guarding), diluting the sperm of previous mates (sperm loading), and removing the sperm of previous mates (sperm displacement), all of which will lead to increased fertilization success for the last mated male (Alcock 1994, Parker 1998). L. vulgaris reynaudii and L. pealei males copulate for a relatively short duration - not due to disturbance by other males, but to a change in behavior to guarding of the females after copulation; during this period, the males remain near the female and chase away other males (Hanlon 1996, Hanlon et al. 2002). In contrast, males of L. opalescens stay conjoined in the male-parallel mating position (Hanlon et al. 2004). These 2 mate-guarding strategies have been observed in insect males; the most familiar examples involve dragonflies and damselflies (Alcock 1994). Two mate-guarding strategies are observed in dragonfly species: some pairs remain in tandem throughout oviposition, while the remainder separates before completion of oviposition and the male continues to guard by remaining near the female and chasing away other males. The switch in males from mating to guarding behavior is related to the amount of interference from other males experienced during the early stages of tandem oviposition (Convey 1989). The male competitive intensity can differ between species and/or situations in squid spawning aggregations. When competition among males for females is high, this could lead to pro- 
longed copulation to guard mates more tightly. The captive conditions and experimental design in the present study could have affected the competitive intensity, so this idea has to be considered carefully with further in situ observations. However, it does suggest that captive experiments, in which the male competitive intensity (e.g. operational sex ratio, male body size) is manipulated, have a great potential in helping to better understand mate-guarding strategies. Sperm displacement has not been studied in detail in squids, but behavioral observations indicate it occurs in other cephalopods. Cuttlefish copulate only in the head-tohead position, and males spend more than half of the copulation period blowing water around the female's seminal receptacles to displace spermatophores from previous mates (Hanlon et al. 1999, Naud et al. 2004). Males of the pygmy octopus Octopus joubini transfer spermatophores into a female's mantle cavity, and those that mate with females who have recently mated with other males prolong the initial period of copulation before transferring spermatophores, presumably to displace previously deposited sperm using their hectocotylus (Cigliano 1995). In future studies, the reason for prolonged copulation in Loligo bleekeri can best be determined by observing if the copulative period is prolonged before the transfer of spermatophores (sperm displacement hypothesis), during the transfer (sperm loading hypothesis), or after the transfer (copulatory guarding hypothesis).

In the second spawning in Trial A, the sneaker male (A-M2) sired $8.5 \%$ of the offspring, which was a higher percentage than the rates for males that mated before the start of the experiment (A-3, B-3, B-4, and C-3). However, those offspring could have resulted from the male-parallel mating by A-M2 before the first spawning, so the actual effect of sneaking was $\leq 8.5 \%$. Extrapair copulation has never been observed in Loligo bleekeri in the field, but it is frequently observed in the laboratory ( 20 to $75 \%$ of male-parallel copulation were sneaked at least once; Y. Iwata unpubl. data). In addition, EPCs have been observed in other loliginid squids, suggesting that it may be a common behavior in this taxon (L. vulgaris reynaudii: Hanlon et al. 1994, 2002; L. pealei: Hanlon 1996). Lone males use multiple tactics to obtain mates, both by fighting a paired male to replace it as a consort, or by performing extra-pair copulations (Hanlon 1998). In loliginid spawning grounds, there are usually more males than females (Hanlon et al. 2004). So the large number of unpaired males will lead to frequent sneaking on the spawning grounds. Hanlon et al. (2002) observed 6 extra-pair copulations during 9 male-parallel copulations in L. vulgaris reynaudii in field. Field observations suggest that lone males appear to frequently immigrate to and emigrate from spawning groups (Hanlon et al. 2004). Such move- ment between reproductive groups is probably adaptive to increase male reproductive success by shortening the time spent in a group and increasing the number of possible mates, suggesting that the fertilization success from a single EPC would be low.

The effect of head-to-head copulation on paternity was also unclear, as males that mated in this position also mated in the male-parallel position. Sperm transferred to the opening of an oviduct by mating in the male-parallel position will be the first to be met when eggs leave the oviduct during spawning, and will thus have an advantage in fertilization. In addition, Loligo vulgaris reynaudii males transfer spermatophores twice during a single male-parallel copulation (Hanlon et al. 2002), so the amount of sperm transferred could be larger in a male-parallel copulation than in a headto-head copulation, which would presumably increase fertilization success. This suggests that the fertilization rate of sperm from the seminal receptacle would be low. This idea is supported by the result that the spermatophores transferred to near the seminal receptacle during 2 EPCs just before spawning sired only $8.5 \%$ of the offspring in the second spawning of Trial A.

In Trial B, the paternity pattern differed among egg capsules; most capsules were sired by a single male that mated both in the male-parallel and head-to-head positions, but several capsules showed multiple paternity (Fig. 3). In Trial A, there was no significant difference in the paternity pattern between egg capsules; most had multiple paternity (Fig. 2). We do not have clear evidence to explain the difference in paternity between egg capsules and/or between broods, because we do not know the position in which the field male mated. But the difference in paternity not only suggests the necessity of analysis using multiple egg capsules to accurately determine parentage, but also suggests the need for further study to better understand sperm storage and release mechanisms. It is unclear if sperm from several males are mixed or stored in layers in the seminal receptacle. The sperm storage mechanism has not been studied in detail in cephalopods, but, in other taxa, sperm stratification occurs in the sperm storage organs. Histology and genetic analysis of mated female snow crabs show that multiple ejaculates are discretely layered from the most recent to the oldest in the spermatheca (Urbani et al. 1998, Saint-Marie et al. 2000). This stratification of recently received sperm on top of previously acquired sperm within the sperm storage organ results in a 'last in-first out' system (Birkhead \& Hunter 1990), and it might result in a paternity difference between the eggs spawned first and those spawned last. An analysis in the order of spawning would be useful. Furthermore, the sperm usage mechanism is more complex in loliginid squids because they have 2 sperm storage sites 
(seminal receptacle and opening of oviduct). Shaw \& Sauer (2004) found that in Loligo vulgaris reynaudii capsules, the distribution of offspring sired by different males is not random, suggesting that sperm from different males are not mixed within sperm storage organs and/or between the 2 sperm storage sites. In the present study, the fertilization rates of the most successful male and the other males did not differ significantly among egg capsules with multiple paternity in either Trial A or Trial B, suggesting that the paternity ratio of the final male to mate in the male-parallel position to the total of previous mates would be constant.

Except for a few sneaker males, loliginid males are larger than females. Such sexual dimorphism is favored when males obtain a size advantage in contests over females, female preferences, and sperm competition (Andersson 1994). Male competition (assessed based on the numbers of rushes and grabs) was more intense between similar-sized males than between different-sized males, and, between different-sized males, larger males attacked smaller males and the frequency of attacks increased as the size difference between males increased (Fig. 1). These results suggest that larger male size gives an advantage in contests for females. But the copulative success in the male-parallel position did not depend on body size (Fig. 1). It is possible that larger males could not disperse other males completely, which would allow smaller males to approach females, due to the closed captive conditions in the present study. Large body size might not be needed for males to successfully mate in the male-parallel position. In the giant Australian cuttlefish Sepia apama, which shows sexual size dimorphism (males are larger than females) and male size dimorphism, females reject most mating attempts (43 to $70 \%$ ) and sometimes reject large males but accept small males (Hall \& Hanlon 2002, Naud et al. 2004). Boal (1997) suggested that female preference in the cuttlefish $S$. officinalis is determined by olfactory cues rather than visual cues. However, mating success is not the same as fertilization success. The present study suggests that the individual fertilization success varies depending on the mating position, timing, and frequency. Hall \& Hanlon (2002) showed that in $S$. apama, large males tend to form pairs with females for longer duration than small ones do. Large body size and superior fighting ability would be favorable for prolonged copulation and postcopulatory guarding.

In summary, this study used both behavioral observations and genetic analysis to show multiple mating and multiple paternity in Loligo bleekeri. The male to mate last and frequently before the female spawned fertilized the most eggs. Paternity rates differed depending on the complex of factors, mating position, timing, frequency and duration. Alternative reproductive behaviors would change factors and lead to different paternity rates. Further analysis with larger samples is needed to confirm the prediction that the final male to mate before a female spawns will sire the most eggs. These results suggest that studies of loliginid mating systems have a great deal of potential in helping us to understand the evolution of alternative reproductive strategies.

Acknowledgements. We thank Dr. John R. Bower for reading the manuscript and offering many valuable comments. We also thank the staff and students of Hokkaido University's Northern Biosphere Field Science Center for their support throughout the captive trials. This study was partly funded by a Science Research Grant from Hakodate City, Japan.

\section{LITERATURE CITED}

Alcock J (1994) Postinsemination associations between males and females in insect: the mate-guarding hypothesis. Annu Rev Entomol 39:1-21

Andersson M (1994) Sexual selection. Princeton University Press, Princeton, NJ

Birkhead TR, Hunter FM (1990) Mechanisms of sperm competition. Trends Ecol Evol 5:48-52

Birkhead TRM, Møller AP (1998) Sperm competition, sexual selection and different routes to fitness. In: Birkhead TRM, Møller AP (eds) Sperm competition and sexual selection. Academic Press, New York, p 757-781

Boal JG (1997) Female choice of males in cuttlefish (Mollusca: Cephalopod). Behaviour 134:975-988

Buresch, KM, Hanlon RT, Maxwell MR, Ring S (2001) Microsatellite DNA markers indicate a high frequency of multiple paternity within individual field-collected egg capsules of the squid Loligo pealeii. Mar Ecol Prog Ser 210:161-165

Cigliano JA (1995) Assessment of the mating history of female pygmy octopuses and a possible sperm competition mechanism. Anim Behav 49:849-851

Convey P (1989) Post-copulatory guarding strategies in the non-territorial dragonfly Sympetrum sanguineum (Müller) (Odonata: Libellulidae). Anim Behav 37:56-63

DiMarco FP, Hanlon RT (1997) Agonistic behavior in the squid Lologo plei (Loliginidae: Teuthoidea): fighting tactics and the effect of size and resource value. Ethology 103:89-108

Drew GA (1911) Sexual activities of the squid, Loligo pealii (Les.). I. Copulation, egg-laying, and fertilization. J Morph 22:327-359

Emery AM, Wilson IJ, Craig S, Boyle PR, Noble LR (2001) Assignment of paternity groups without access to parental genotypes: multiple mating and developmental plasticity in squid. Mol Ecol 10:1265-1278

Gross MR (1996) Alternative reproductive strategies and tactics: diversity within sexes. Trends Ecol Evol 11:92-98

Hall KC, Hanlon RT (2002) Principal features of the mating system of a large spawning aggregation of the giant Australian cuttlefish Sepia apama (Mollusca: Cephalopoda). Mar Biol 140:533-545

Hamabe M, Shimizu T (1957) The copulation behavior of yariika, Loligo bleekeri K. Rep Jpn Sea Reg Fish Res Lab 3: 131-136 
Hanlon RT (1996) Evolutionary games that squids play: fighting, courting, sneaking, and mating behaviors used for sexual selection in Loligo pealei. Biol Bull (Woods Hole) 191:309-310

Hanlon RT (1998) Mating systems and sexual selection in the squid Loligo: how might commercial fishing on spawning squids affect them? CALCOFI (Calif Coop Ocean Fish Investig) Rep 39:92-100

Hanlon RT, Messenger JB (1996) Cephalopod behaviour. Cambridge University Press, Cambridge

Hanlon RT, Smale MJ, Sauer WHH (1994) An ethogram of body patterning behavior in the squid Loligo vulgaris reynaudii on spawning grounds in South Africa. Biol Bull (Woods Hole) 187:363-372

Hanlon RT, Maxwell MR, Shashar N (1997) Behavioral dynamics that would lead to multiple paternity within egg capsules of the squid Loligo pealei. Biol Bull (Woods Hole) 193:212-214

Hanlon RT, Ament SA, Gabr H (1999) Behavioral aspects of sperm competition in cuttlefish, Sepia officinalis (Sepioidea: Caphalopoda). Mar Biol 134:719-728

Hanlon RT, Smale MJ, Sauer WHH (2002) The mating system of the squid Loligo vulgaris reynaudii (Cephalopoda, Mollusca) off South Africa: fighting, guarding, sneaking, mating and egg laying behavior. Bull Mar Sci 71:331-345

Hanlon RT, Kangas N, Forsythe JW (2004) Egg-capsule deposition and how behavioral interactions influence spawning rate in the squid Loligo opalescens in Monterey Bay, California. Mar Biol 145:923-930

Iwata Y, Munehara H, Sakurai Y (2003) Characterization of microsatellite markers in the squid, Loligo bleekeri (Cephalopoda: Loliginidae). Mol Ecol Notes 3:392-393

Jones AG (2001) GERUD1.0: a computer program for the reconstruction of parental genotypes from progeny arrays using multilocus DNA data. Mol Ecol Notes 1:215-218

King AJ, Adamo SA, Hanlon RT (1999) Contact with squid egg capsules increases agonistic behavior in male squid (Loligo pealei). Biol Bull (Woods Hole) 197:256

Maxwell MR, Hanlon RT (2000) Female reproductive output in the squid Loligo pealeii: multiple egg clutches and implications for a spawning strategy. Mar Ecol Prog Ser 199:159-170

Moczek AP, Emlen DJ (2000) Male horn dimorphism in the

Editorial responsibility: Don Levitan (Contributing Editor), Tallahassee, Florida, USA scarab beetle, Onthophagus taurus: do alternative reproductive tactics favour alternative phenotypes? Anim Behav 59:459-466

Natsukari Y, Tashiro M (1991) Neritic squid resources and cuttlefish resources in Japan. Mar Behav Physiol 18:149-226

Naud M, Hanlon RT, Hall KC, Shaw PW, Havenhand JN (2004) Behavioural and genetic assessment of reproductive success in a spawning aggregation of the Australian giant cuttlefish, Sepia apama. Anim Behav 67:1043-1050

Parker GA (1998) Sperm competition and the evolution of ejaculates: towards a theory base. In: Birkhead TRM, Möller AP (eds) Sperm competition and sexual selection. Academic Press, New York, p 3-54

Perez JAA, Aguiar DC, Oliveira UC (2002) Biology and population dynamics of the long-finned squid Loligo plei (Cephalopoda: Loliginidae) in southern Brazilian waters. Fish Res (Amst) 58:267-279

Raymond M, Rousset F (1995) Genepop (Version 1.2): population genetics software for exact tests and ecumenicism. J Hered 86:248-249

Roper CFE, Sweeney MJ, Nauen CE (1984) FAO species catalogue, Vol 3. Cephalopods of the world: an annotated and illustrated catalogue of species of interest to fisheries. FAO Fish Synop 125 (3)

Saint-Marie G, Saint-Marie B, Sévigny JM (2000) Ejaculatestorage patterns and the site of fertilization in female snow crabs (Chionoecetes opilio; Brachyura, Majidae). Can J Zool 78:1902-1917

Shaw PW, Boyle PR (1997) Multiple paternity within the brood of single females of Loligo forbesi (Cephalopoda: Loliginidae), demonstrated with microsatellite DNA markers. Mar Ecol Prog Ser 160:279-282

Shaw PW, Sauer WHH (2004) Multiple paternity and complex fertilization dynamics in the squid Loligo vulgaris reynaudii. Mar Ecol Prog Ser 270:173-179

Urbani N, Saint-Marie B, Sévigny JM, Zadworny D, Kuhnlein U (1998) Sperm competition and paternity assurance during the first breeding period of female snow crab (Chionoecetes opilio) (Brachyura: Majidae). Can J Fish Aquat Sci 55:1104-1113

Yamamura N (1986) An evolutionarily stable strategy (ESS) model of postcopulatory guarding in insects. Theor Popul Biol 29:438-455

Submitted: January 13, 2005; Accepted: May 19, 2005 Proofs received from author(s): July 26, 2005 